\title{
Development of Induction Machines in Wind Power Technology
}

\author{
Stefan Soter, Member, IEEE, Ralf Wegener, Student Member, IEEE \\ Institute of Electrical Drives and Mechatronics \\ University of Dortmund, Germany \\ http://eam.e-technik.uni-dortmund.de \\ Stefan.Soter@ieee.org, Tel: +49 231755 2721; \\ Ralf.Wegener@uni-dortmund.de, Tel: +49 231755 6174;
}

\begin{abstract}
This paper gives an overview of the development of the induction machine as a generator for wind turbines from the middle of the 20th century up to now. After a short history chapter the different energy conversion concepts are presented. At first a squirrel cage machine is direct coupled to the grid (Danish concept). To adjust the machine speed the second step is a wound rotor machine with collector rings to change rotor resistance. This concept allows the first adaption of the operating point of the wind turbine and the induction machine. Another concept is to connect the stator of a squirrel cage machine with a full inline voltage source converter to the grid to get the flexibility in rotational speed and to control the reactive power. The doubly fed induction machine is the latest development. This concept uses a bidirectional voltage source converter in the rotor circuit with a rated power of only $30 \%$ of the rated generator power. Now it is possible to change the rotational speed and the reactive power independently and in a wide range. A generalized control scheme of a modern doubly fed induction machine (DFIG) is shown in the last part to explain the variability and the range of application. Today over $70 \%$ of the wind turbines are build up with DFIG.
\end{abstract}

Keywords_-Induction Machines, DFIG, Wind Power

\section{History OF INDUCTION GENERATORS IN WINDMILLS}

The energy of the wind is used for more than thousand years. The first history proven usage has been around the year 650 in Tibet for religious aims. These early models are vertical axis wind turbines based on the principle of scoop drag-type devices which are today used only in anemometers. At the beginning of the second millennium horizontal axis windmills became popular mainly in southern Europe and the Netherlands for pumping water.

The first production of electrical energy with wind power was done in 1887 by Charles Brush in Cleveland, Ohio. The rated Power of the used dc-generator was $12 \mathrm{~kW}$ and was designed to charge batteries. The induction machine was used at the first time in 1951.

\section{ENERGY CONVERSION CONCEPTS}

There exists several basic principles of producing electrical power with wind energy and induction machines.

\section{A. Fixed Speed Wind Generator}

The easiest principle is to connect a squirrel cage induction machine with a gearbox directly to the grid. This is called the Danish concept (see figure 1). The gearbox is necessary to convert the low rotational speed of the wind rotor to a compatible frequency of the available grid, for example around 1500rpm in

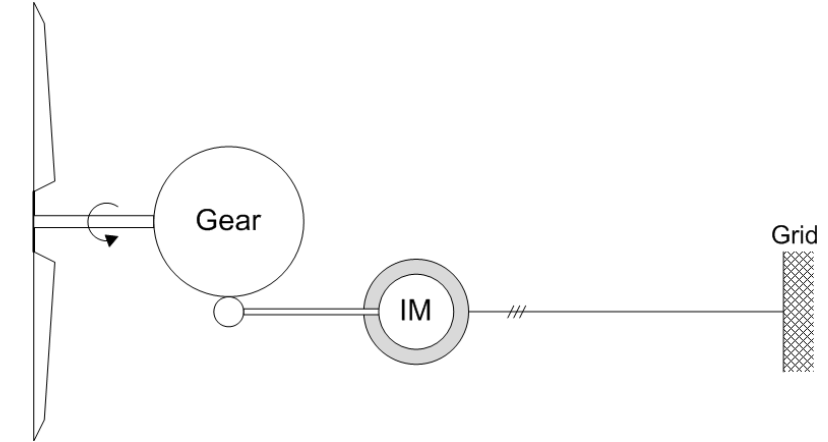

Fig. 1. Danish concept - fixed coupled induction machine

case of a 4-pole generator in the European $50 \mathrm{~Hz}$ grid. The rotational speed of the wind turbine depends on the diameter of the blades. A common squirrel cage machine with a rated power of $600 \mathrm{~kW}$ and a blade diameter of $44 \mathrm{~m}$ uses $26 \mathrm{rpm}$ for the turbine. The maximum speed at the tip of the blade is $60 \mathrm{~m} / \mathrm{s}$.

The Danish concept has the major benefit of a very simple construction of the whole wind turbine with very low investment and maintenance costs. No power converter or complex controller is needed. The major disadvantage is the fixed rotational speed. This is important for several aspects:

$\ominus$ The blades are not in the optimal operating point for a wide wind speed range.

$\ominus$ The electrical power of the generator cannot be regulated quickly because the only possibility to influence is the pitchangle of the blades.

$\ominus$ Wind gusts and the back pressure of the tower result directly in power fluctuations.

To reduce this disadvantages, it is possible to build a generator with a higher slip ratio, because slip means elasticity of the system. In figure 2 a slip versus rated power diagram of standard industrial machines is shown. The over-all tendency is the increasing slip with higher number of poles. A six or eight pole generator has a higher elasticity than a generator with two poles. This elasticity is required to reduce the power fluctuations, which stresses the drive train and causes power peaks in the grid. In figure 3 two diagrams show the power fluctuation of a squirrel cage machine with $2 \%$ rated slip on the left side and with $8 \%$ rated slip on the right side. A generator with $2 \%$ rated slip causes power fluctuations in the range of $20 \%$ of rated power, 


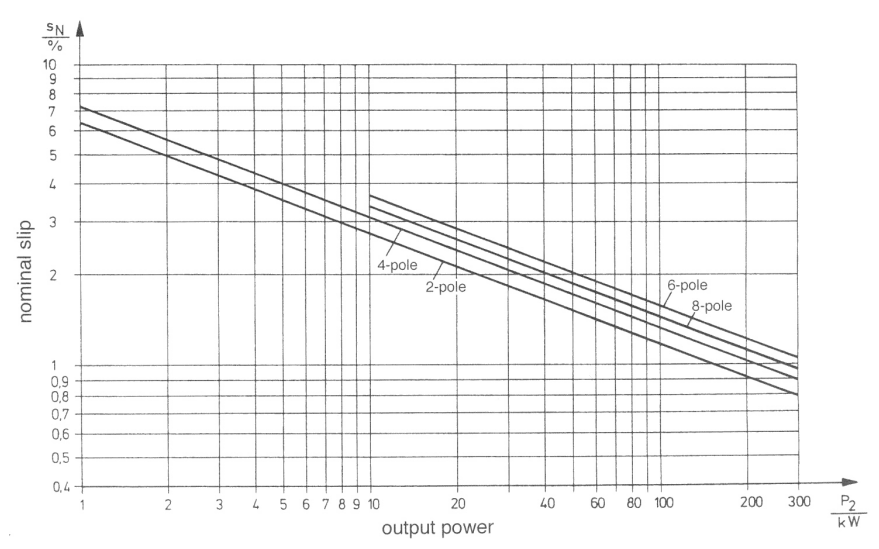

Fig. 2. Slip as a function of rated power (parameter pole numbers)
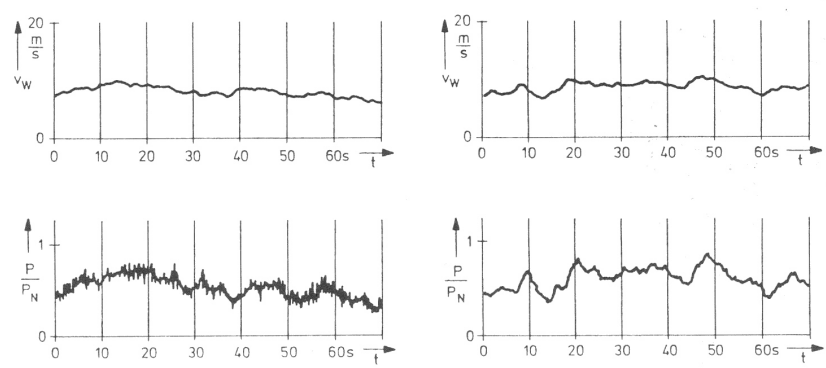

(a) $2 \%$ rated slip

(b) $8 \%$ rated slip

Fig. 3. Power fluctuation of a squirrel cage machine (parameter rated slip)

one with $8 \%$ operates with only $5 \%$. The variability in the time domain of seconds is a result of wind speed which clearly can be recognized in figure 3. In the Danish concept the generator is directly coupled to the grid, so the only way to reduce the dynamic loads of drive train and grid is to design a generator with a high number of poles. This has the disadvantage of increasing volume and masses of the generator and lowers the efficiency of the whole system.

In figure 4 an array of characteristic curves of direct grid-coupled

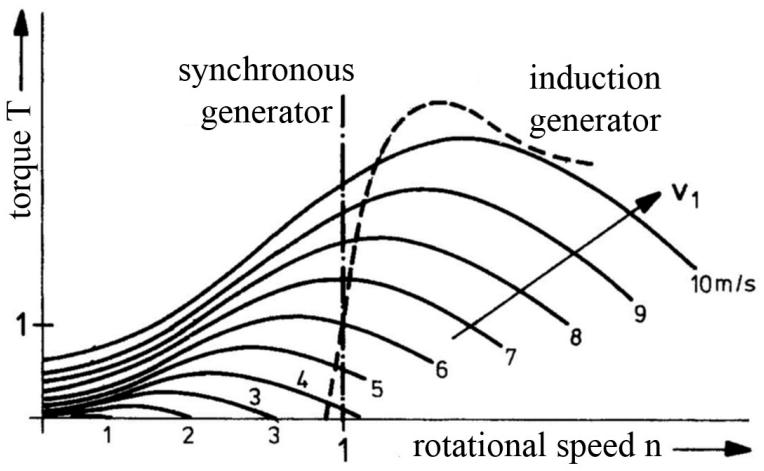

Fig. 4. Characteristic curves of wind turbines with fixed speed generators

wind turbines is described and parameterized by wind speed. The rated wind speed is $6 \mathrm{~m} / \mathrm{s}$ and in this operating point the characteristic curve of the induction generator fits perfect. With in- creasing wind speed the speed of the generator lowers and with decreasing wind speed the speed of the generator is higher. This behavior is possible by changing the slip over a range of several percent. If the wind speed is below $4 \mathrm{~m} / \mathrm{s}$, no delivery of power to the grid is possible.

To avoid this problem the first step was to build wind turbines with two generators, one for weak wind condition with lower rated power and lower rotational speed and the other for the strong wind conditions. For example a $600 \mathrm{~kW}$ rated power wind turbine operates with a generator of $200 \mathrm{~kW}$ in weak wind conditions and with the $600 \mathrm{~kW}$ generator in strong wind conditions. The other possibility is only one generator with a switchable number of poles to adapt different wind speeds. An operating diagram is shown in figure 5. The diagram describes the characte-

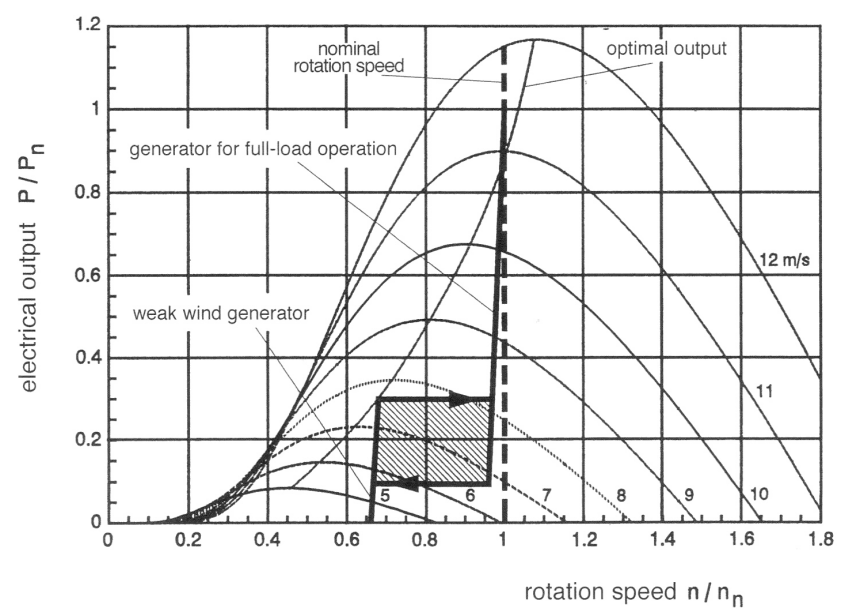

Fig. 5. Characteristic curves of wind turbines with two fixed speed generators

ristic array of curves of output power as a function of rotational speed.The rated operating point of the strong wind generator is at $11 \mathrm{~m} / \mathrm{s}$ wind speed and the weak wind generator works optimal at $7.5 \mathrm{~m} / \mathrm{s}$. There has to be a hysteresis between the switching points of the weak and the strong wind generator to avoid unnecessary dynamic loads to the mechanical and electrical components by switching frequently.

\section{B. Adjustable Speed Wind Generator}

Adjustable speed generators which are very common in modern wind turbines have several advantages:

$\oplus$ Mechanical stress of all parts of the turbine can be reduced because wind gusts can be absorbed by the inertia of the turbine. $\oplus$ Power fluctuations in the grid are reduced because the impacts of the wind are buffered in mechanical energy and are not passed onto the grid. Even the back pressure of the tower can be compensated (see figure 7).

$\oplus$ The system efficiency is improved by the adaption of the rotational speed as a function of the wind speed. The maximum output power can be achieved over a wide wind speed range (see figure 14).

$\oplus$ The pitch control can be simpler because the time constant can be longer with variable speed [2].

$\oplus$ The noise emission is reduced in weak wind conditions because the turbine is rotating with lower speed. 
The first way to get an adjustable speed generator for a reasonable price is to change over from squirrel cage induction machine to a wound rotor machine with collector-rings. By changing the rotor resistor it is possible to adapt the operating point of the induction machine in order to get a better adaption in start-up, weak wind condition and strong wind condition. With this tech-

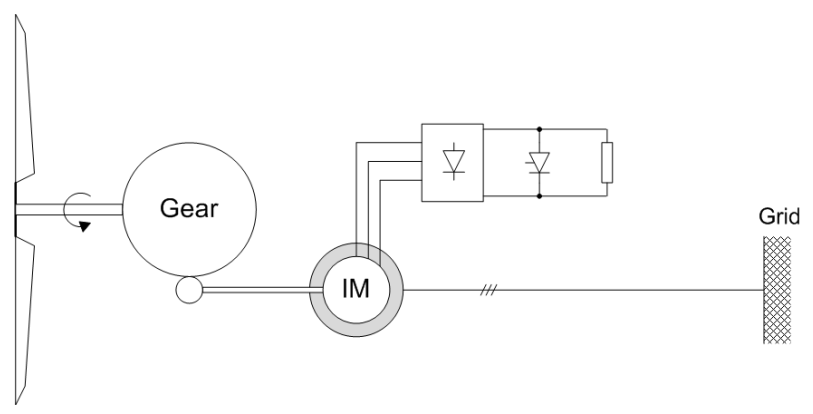

Fig. 6. Induction generator with variable rotor resistor

nique it is also possible to change the rotor resistance in a very dynamic way. In figure 7 the torque, the output power and the slip is plotted. The torque curve lowers dramatically when one rotor blade rides through the back pressure zone of the tower. If a very dynamic slip control allows the adjustment of the rotor resistance as shown in the diagram it is possible to compensate this effect in the power dissipation to the grid.

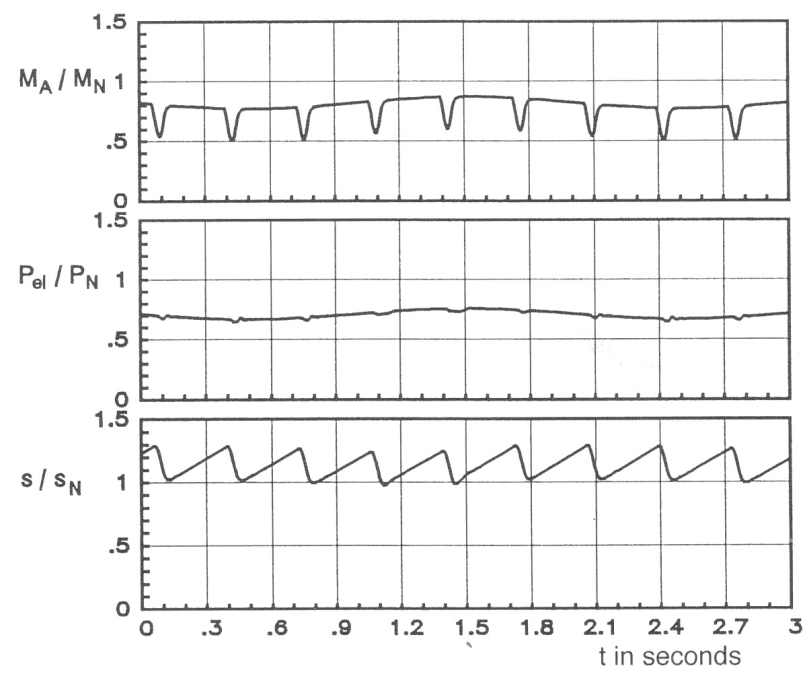

Fig. 7. Induction generator with variable rotor resistor

There are several principles more to build up adjustable speed wind turbines. One possibility is to change the Danish concept in the electrical connection with a direct in line frequency converter (VSC) which connects the stator of the generator with the grid (see figure 8). In this concept the generator has not to be changed but several disadvantages are apparent:

$\ominus$ The frequency converter has to be dimensioned for the maximum power of the turbine and therefore it is expensive.

$\ominus$ The converter efficiency effects the entire power and has to be very high over the full power range to guarantee high performance.

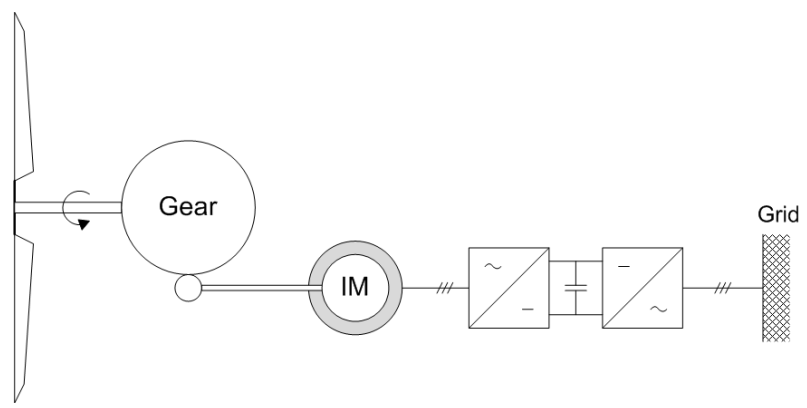

Fig. 8. Variable speed induction generator with full powered converter

The reasons for choosing this topology are:

$\oplus$ The power factor can be controlled in a wide range.

$\oplus$ Wind gusts can not only buffered in the mechanical inertia but in the energy storage of the intermediate circuit [1].

$\oplus$ The squirrel-cage induction machine is very rugged and causes few maintenance costs.

In figure 9 an array of characteristic curves are described. The variation of the stator frequency allows to adjust the characteristic curve of the squirrel cage induction machine. The power electronic adapts the operating point of the generator to the different operating points of the wind turbine.

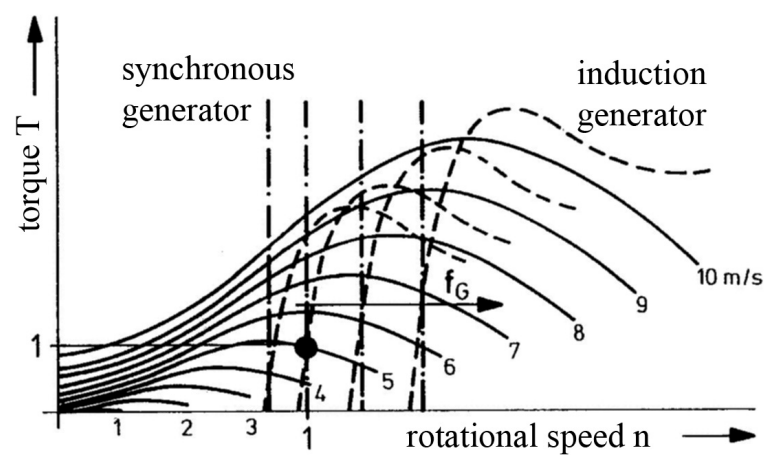

Fig. 9. Characteristic curves of wind turbines with full powered converter

\section{Doubly Fed Induction Generator}

The doubly fed induction machine became more and more common in wind power generation. Today more than $70 \%$ of the build wind turbines are equipped with this type of induction machine. Usually the voltage source converter is connected with the machine side to the wound rotor via collector rings. The grid side converter and the stator of the induction machine are directly connected to the grid (see figure 10). A few years ago a transformer has to be placed between converter and the grid to adapt the voltages. Today it is not necessary any more, because it is possible to dimension the rotor windings and the power electronics, that the rotor voltage even in the area of low rotor frequencies (synchronous operating point) is high enough to feed into the grid only by using an inductance.

This system has the following assets and drawbacks:

$\oplus$ The costs of the converter are reduced, compared to the full inline converter, because it is rated for only $30 \%$ of the total 


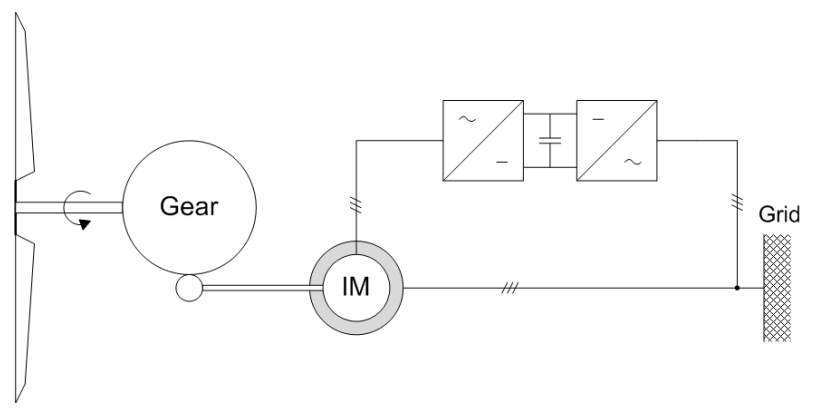

Fig. 10. Doubly fed induction generator

power of the generator.

$\oplus$ The emc-filters are cheaper because of the lower power, too.

$\ominus$ The wound rotor induction machine is not as rugged as the squirrel case machine. Collector rings are necessary and have to be maintained regularly.

$\ominus$ A complex control is necessary.

\section{Non Induction Machines}

A synchronous generator with separate excitation is used mainly by one company in Europe to build a gearless wind turbine. Although it is not mainly discussed in this paper the main attributes should be described shortly:

$\oplus$ Because of the abolition of the gearbox the turbine is more reliable and needs less maintenance.

$\oplus$ A direct inline converter is necessary like in figure 11 with its above described advantages but high costs.

$\ominus$ The synchronous machine has to have a high number of poles (100 to 300) which results in machines with large diameter.

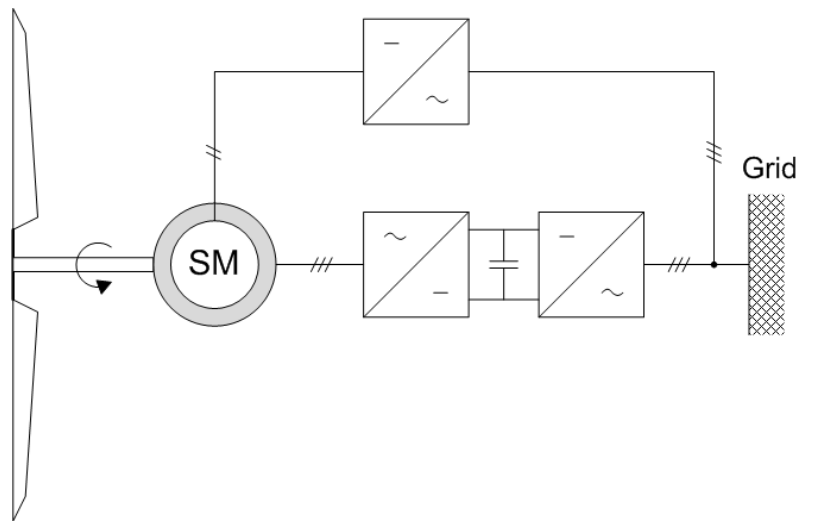

Fig. 11. Synchronous generator without gear

Other types of machines like dc-generators, permanent magnet machines or variable-reluctance generators are not important in the state of the art market in wind power generation [2]. The prices for special magnets $(\mathrm{NdFeB})$ decreased extremely in the last years. So it could be interesting to build up wind power generators with permanent magnet machines. In spite of the difficulties in handling, corrosion, long time stability and control of the system first pilot plants are build.

\section{Components of A State of the ARt Wind Power NACELLE}

In figure 12 the outline of a nacelle of a state of the art wind turbine from Nordex is shown.

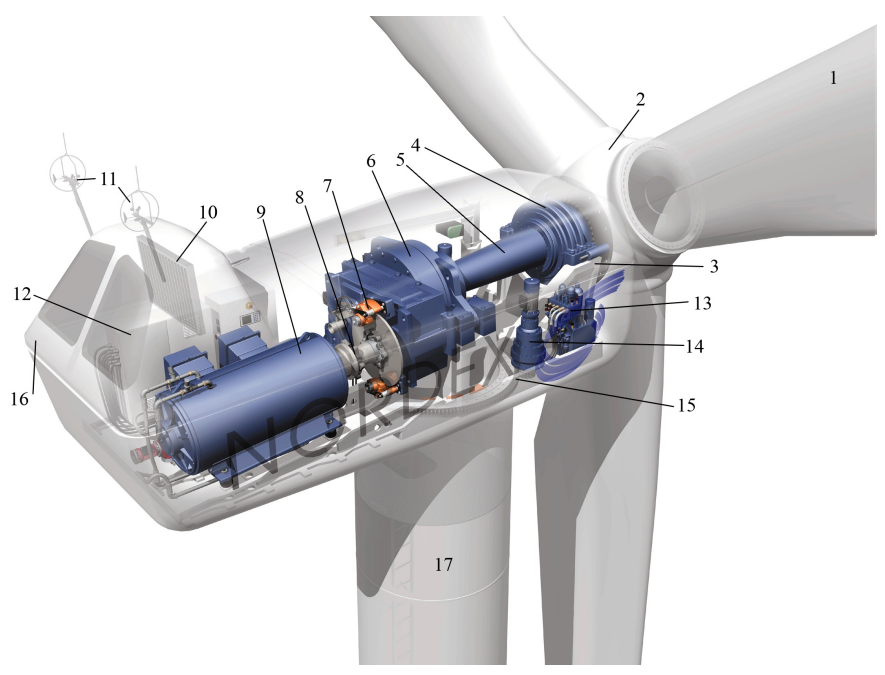

Fig. 12. Nacelle of a state of the art wind turbine
1. rotor blade

2. rotor hub

3. nacelle frame

4. main bearing

5. rotor shaft

6. gearbox

7. safety brake

8. generator coupling

9. induction generator
10. generator and gearbox cooler

11. wind sensors

12. nacelle control

13. hydraulic system

14. yaw drive

15. yaw bearing

16. nacelle cover

17. tower
Modern wind turbines are build with a rotor hub (2) and three rotor blades (1), each of them is independently and redundant adjustable in pitch angle. The main bearing (4), which has to absorb all the static and dynamic loads, supports the rotor shaft (5). In the gearbox (6) the low speed of the blades is transformed to the nominal speed of the induction generator(9). In the drive train in between the gearbox and the generator a safety brake (7) and a coupling is located. All this heavy components are mounted on the nacelle frame (3). A special cooler (10) for the generator and the gearbox is needed to control the temperatures in high wind or high temperature operating points. A control unit (12) and an hydraulic system is placed in the nacelle, too. The complete nacelle with its cover (16) is mounted on the tower (17) with a yaw bearing (15). Dependent of the wind direction, which is measured by wind sensors (11) the yaw drive (14) aligns the nacelle.

In figure 14 a characteristic output power curve of the Nordex N90 wind turbine with a rated power of $2300 \mathrm{~kW}$ is plotted. The plant starts generation at a wind speed of $3.5 \mathrm{~m} / \mathrm{s}$ with an optimal pitch angle and very low speed of $10 \mathrm{rpm}$. The control mode of speed variation is possible up to a wind speed of $12.5 \mathrm{~m} / \mathrm{s}$. At this operating point the rated power is produced and the maximum speed of $17 \mathrm{rpm}$ is achieved. 


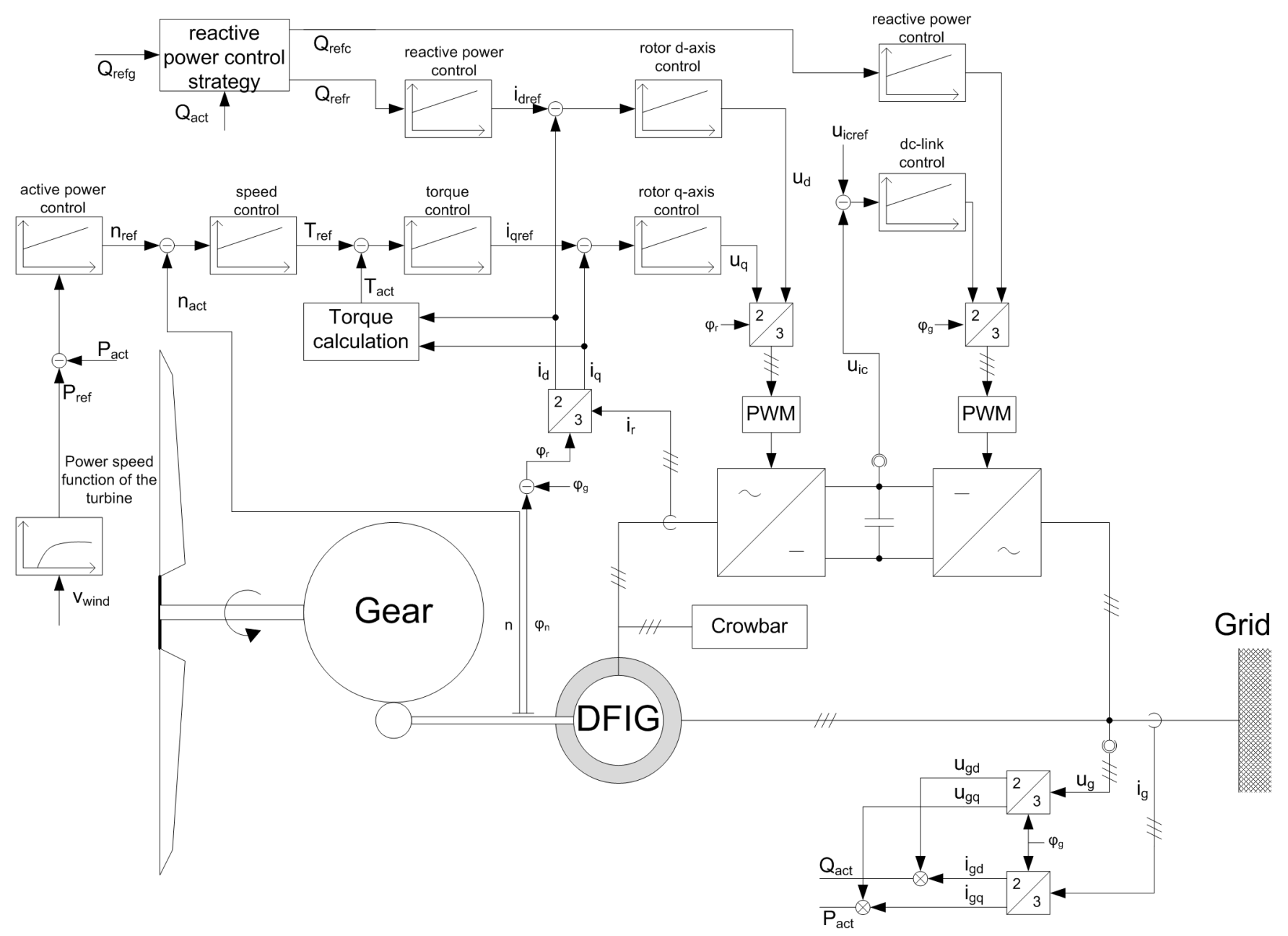

Fig. 13. control-scheme of a typical doubly fed induction generator in used for wind turbines.

From this wind speed up to the maximum possible operating wind speed at $25 \mathrm{~m} / \mathrm{s}$ the control mode of pitch angle variation is used. If the wind speed is higher than $25 \mathrm{~m} / \mathrm{s}$ the wind turbine has to shut down in order to avoid damages. When the wind speed is lower the wind turbine can start up again.

\section{CONTROL}

The control of a wind power generator can be divided into two main parts, the machine control and the system control. The system control is for example responsible to align the nacelle into the wind. The machine control depends on the type of machine. A generalized control of a doubly fed induction generator is shown in figure 13. The voltage source converter which deals approximately $30 \%$ of the whole generator power is divided into two separate structures, which are controlling the motor respectively the grid side independently. The grid side of the converter is responsible of the intercircuit voltage and has to control the power flow from or to the grid. This is done by controlling the active power axis of the grid converter in either direction dependent of the dc intercircuit voltage.

In modern devices the reactive power can be controlled separately to give the possibility to adjust the total power factor of the system in a wide range due to the necessities of the grid. In this case the control scheme of the grid converter is also done with a vector control to regulate the active power in the intercircuit voltage in the above described way and the reactive power to the grid by a superior reactive power control strategy. In former turbines this control is omitted and the reactive power of the converter is set to zero. In this case the total reactive power of the system can only be set indirectly by the d-axis of the rotor side.

The machine side converter is controlled usually by a vector control scheme in $\mathrm{d}-\mathrm{q}$ coordinates which allows also to control flux and torque separately. The d-axis contains a pid-controller for the current and the power controller for the reactive power of the machine. The setpoint of this controller is given from the above mentioned reactive power control strategy to set the total power factor of the system.

The q-axis of the rotor side converter is controlled in the inner loop by the current controller which gets the reference value from the torque control. The current feedback is measured in at least two phases of the rotor side and is converted to the d-q system. In most cases all three phase currents are measured to give a redundancy. In the shown control scheme the resistance of the stator is neglected which can be easily added in real turbines. 
The actual torque of the machine is calculated from the $\mathrm{d}$ and q current and is compared to the output of the speed controller [12], [13]. The reference turbine-speed is set by the active power control which generates the optimal speed of the turbine with a lookup table and the measured wind speed. This is necessary to control the revolution speed of the turbine (see figure 9). The wind speed is measured independently for example with an anemometer.

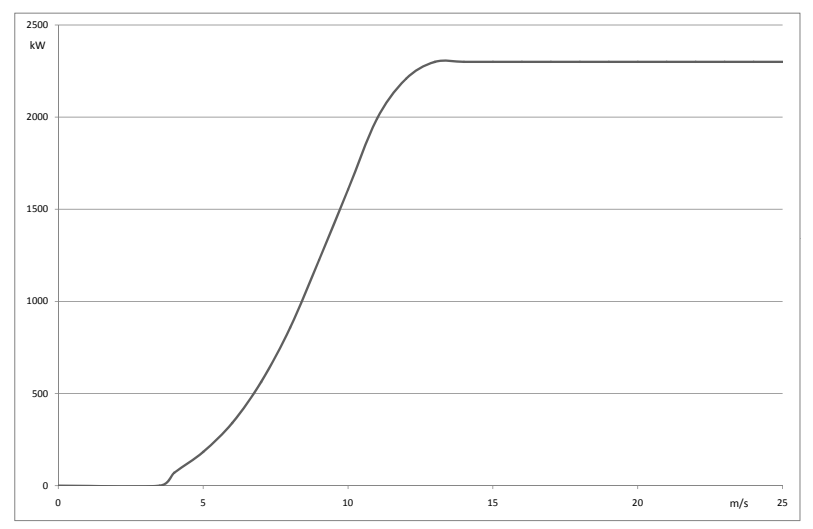

Fig. 14. Power curve of the Nordex N90 2,3MW Turbine.

The actual value of the active and reactive power is calculated by the grid voltages and currents which is shown in a simplified manner. The phase angle $\varphi_{g}$ is calculated, too, which is necessary to transform the voltages and currents into the d-q coordinates.

In case of a sudden disconnection of the generator from the grid due to for example circuit breaker or short breaks, high voltage pulses in the rotor circuit can occur. To protect the rotor side converter a so called crowbar is usually implemented which short circuits the rotor of the generator. After a short while the control disconnects the stator from grid with ordinary circuit breakers [3]. The problem of this protection is the grid code which demanded often a fault ride through. This is not possible in case of a crowbar activation because the whole turbine has to be restarted.

\section{CONCLUSION}

The development of the induction machine in wind power technology from a squirrel cage machine to a doubly fed induction machine shows the tremendous potential of this kind of electrical generator. The first wind turbines with squirrel cage machine were build in the late 1980s with a rated power of less than $100 \mathrm{~kW}$. The state of the art wind turbines with doubly fed induction machine have a rated power up to 5.0MW. Theses turbines are constructed for a very high efficiency, performance and very low maintenance in order to go offshore with the next generation of wind turbines.

\section{REFERENCES}

[1] S. Müller, M. Deicke, R. De Doncker Doubly fed induction generator systems for wind turbines, Industry Applications Magazine, IEEE, May-June 2002 Volume: 8 , Issue: 3 , pages: $26-33$

[2] J. Marques, et al. A Survey on Variable-Speed Wind Turbine System, Congresso Brasileiro de Eletrônica de Potência (COBEP), 2003, Fortaleza - CE.
[3] A. Petersson, L. Harnefors, T. Thiringer Evaluation of Current Control Methods for Wind Turbines Using Doubly-Fed Induction Machines, IEEE Transactions on Power Electronics, Vol. 20, No. 1, January 2005, Pages 227-235

[4] B. Shen, V. Low, B. Ooi Slip frequency phase lock loop (PLL) for decoupled $P-Q$ control of doubly-fed induction generator $(D F I G)$, Industrial Electronics Society, 2004. IECON 2004. 30th Annual Conference of IEEE, 2-6 Nov. 2004

[5] G. Poddar, V. Ranganathan Sensorless field-oriented control for doubleinverter-fed wound-rotor induction motor drive, IEEE Transactions on Industrial Electronics - Volume 51 (2004) Issue 5, pages 1089-1096

[6] E. Bogalecka, M. Wierzejski Control system of a double-fed induction machine working as a generator, PCIM 1991, Europe Official Proceedings of the Nineteenth International Intelligent Motion Conference (1991) pages 104-112

[7] O. Mohammed, Z. Liu, S. Liu A Novel Sensorless Control Strategy of Doubly Fed Induction Motor and Its Examination With the Physical Modeling of Machines, IEEE Transactions on Magnetics, Vol. 41, No. 5, May 2005 pages 1852-1855

[8] H. Späth Steuerverfahren für Drehstrommaschinen: Theoretische Grundlagen, Berlin, Germany, Springer-Verlag, 1983

[9] H. Stemmler, A. Omlin Converter controlled fixed-frequency variablespeed motor/generator, IPEC 1995, Japan

[10] Z. Lubosny Wind Turbine Operation in Electric Power Systems, Berlin, Germany, Springer-Verlag, 2003

[11] L. Freris Wind Energy Conversion Systems, Prentice Hall International Ltd, UK, 1990

[12] S. Heier Windkraftanlagen, Teubner Verlag, Germany, 2005

[13] S. Heier Grid integration of wind energy conversion systems, Wiley, 1998

[14] D. Rajib, V. Ranganathan Variable-Speed Wind Power Generation Using Doubly Fed Wound Rotor Induction Machine - A Comparison with alternative Schemes, IEEE Transactions on Energy Conversion, Vol. 17, No. 3, September 2002, Pages 414-421

[15] F. Iov, F. Blaabjerg, A Hansen Analysis of a variable-speed wind energy conversion scheme with doubly-fed induction generator, International Journal of Electronics, 2003, Vol. 90, Nos. 11-12, Pages 779-797

[16] A. Petersson Analysis, Modeling and Control of Doubly-Fed Induction Generators for Wind Turbines, PhD Thesis, University of Technology, Göteborg, Sweden, 2005

[17] P. Carlin, A. Laxson, E. Muljadi The History and State of the Art of Variable-Speed Wind Turbine Technology, Technical Report, National Renewable Energy Laboratory, Colorado, 2001

[18] R. Teodorescu, F. Blaabjerg Flexible Control of Small Wind Turbines With Grid Failure Detection Operating in Stand-Alone and Grid-Connected Mode, IEEE Transactions on Power Electronics, Vol. 19, No. 5, September 2004, Pages 1323-1332

[19] M. Bartram, J. von Bloh, R. De Doncker Doubly-Fed-Machines in Wind-Tirbine Systems: Is this Application Limiting the Lifetime on IGBTFrequency-Converters?, 2004 35th Annual IEEE Power Electronics Specialists Conference, Aachen, germany, 2004, Pages 2583-2587

[20] www.Nordex.de

[21] S Seman, J Niiranen, S Kanerva, A Arkkio Analysis of a 1.7 MVA doubly fed wind-power induction generator during power systems disturbances, Proceedings of NORPIE 2004, 14-16 June 2004, Trondheim, Norway

[22] B. Shen, B. Ooi Novel Sensorless Decoupled P-Q Control of DoublyFed Induction Generator (DFIG) Based on Phase Locking to Gamma-Delta Frame, Power Electronics Specialists Conference, 2005. PESC '05. IEEE 36th, pages: 2670- 2675

[23] J. Rickard Getting wind to the grid [doubly fed induction generators for wind power generation]. , Power Engineer. Vol. 18, no. 4, pp. 30-31. Aug. 2004

[24] R. Carlson, H. Voltolini, F. Runcos, P. Kuo-Peng A Performance Comparision between Brush and Brushless Doubly Fed Asynchronous Generators for Wind Power Systems, International Conference on Renewable Energies and Power Quality, Icrepq 2006.

[25] S. Seman, J. Niiranen, S. Kanerva, A. Arkkio, J. Saitz Performance Study of Doubly Fed Wind-Power Generator under Network Disturbances, IEEE Transaction on Energy Conversion, Accepted for future publication,

[26] B. Chowdhury, S. Chellapillaa Double-fed induction generator control for variable speed wind power generation, Electric Power Systems Research Volume 76, Issues 9-10, June 2006, Pages 786-800

[27] J. Ekanayake, L. Holdsworth, X. Wu, N. Jenkins Dynamic modeling of doubly fed induction generator wind turbines, IEEE Transactions on Power Systems. Vol. 18, no. 2, pp. 803-809. May 2003

[28] D. Aouzellag, K.Ghedamsi, E. Berkouk Power Control of a Variable Speed Wind Turbine Driving an DFIG, International Conference on Renewable Energies and Power Quality, 2006 